\title{
Foreign Body Giant Cells on Intraocular Lens Implants*
}

\author{
J. Reimer Wolter \\ The Departments of Ophthalmology and Pathology of the University of Michigan Hospitals, Ann Arbor, Michigan, USA
}

\begin{abstract}
Foreign body giant cells in cellular membranes on the surface of intraocular lens implants are a typical part of the reaction of the inner eye to these implants. These giant cells are spread to an extremely large size, they may exhibit up to a hundred nuclei, and they often contain phagocytised pigment in their protoplasm. To start a detailed morphological description of these giant cells on lens implants in their appearance and relation to other cells under different conditions is the purpose of the present communication.
\end{abstract}

Zusammenfassung. Fremdkörperriesenzellen in Zellmembranen auf intraokulären Linsenprothesen sind ein typischer Teil der Reaktion des inneren Auges auf diese Prothesen. Die Riesenzellen wachsen zu einer außerordentlichen Größe, sie kömnen bis zu hundert Kerne enthalten und sie zeigen oft phagozytiertes Pigment in ihrem Protoplasma. Es ist das Ziel der vorliegenden Arbeit, die Morphologie der Riesenzellen auf Linsenprothesen in ihrer Erscheinung und in ihrem Verhältnis zu anderen Zellen unter verschiedenen Bedingungen $\mathrm{zu}$ beschreiben.

Foreign body giant cells are a specific cell form, that develops when epithelioid cells expand their protoplasm and form numerous nuclei by nuclear division without cytoplasmic fission. Epithelioid cells, in turn, are sessile histiocytes (macrophages), that have lost their cell processes and enlarged their cell bodies and nuclei. Macrophages are the clean-up cells of the inner eye. They originate in the blood stream (blood monocytes) and develop delicate processes, as they move through the tissues. Macrophages are able to reproduce in tissues. They can appear quickly and in great numbers, when debris - like degenerating lens substance or blood - needs to be cleared $[1,2]$. In the eye macrophages are used for clean-up especially in areas without direct vascular supply. It is confusing, that histiocytes are often called microglia, when they occur in the central nervous system as well as in retina or optic nerve.

\footnotetext{
* Supported by The Research To Prevent Blindness, Inc., New York
}

Offprint requests to: J. Reimer Wolter, M.D., Department of Ophthalmology, University of Michigan Hospitals, Ann Arbor, Michigan 48109
Foreign body giant cells typically are part of a tissue response known as foreign body reaction. Stated in simple terms, foreign body giant cells aim to encorporate as much of a foreign body as possible in their protoplasm with the aim to separate it from the surrounding tissues and to digest it. Small foreign bodies are, thus, commonly found in the protoplasm of single giant cells. Large foreign bodies, that cannot be encorporated by one giant cell, are typically covered by many giant cells - and these enlarge and flatten out to cover as much as possible of the foreign surface. The process of encorporation of whole foreign bodies or parts of foreign bodies in the protoplasm of giant cells is known as phagocytosis. Phagocytosis is more than encorporation; it goes in most instances along with intraprotoplasmatic digestion of foreign material. The digestive abilities of giant cells are remarkable. With time these cells can digest even some of the more resistant materials. They achieve oxidation of silica to colloidal silica, for example, as a first step in its slow removal [3]. The formation and function of foreign body giant cells is not usually an independent process. These cells are part of the so-called foreign body granuloma. Such a granuloma is not always fully developed, but among its typical additional components are histiocytes, epithelioid cells, fibroblasts and mononuclear inflammatory cells. Polymorph nuclear leucocytes may occur in granulomas with an acute inflammatory component. Eosinophils are common in granulomas due to hypersensitivity reactions. In a well developed foreign body granuloma the fibroblasts form a collagenous capsule and blood vessels develop in and around this. Foreign body granulomas are often delayed in their formation and may be extremely chronic in their course.

A giant cell reaction to localized foreign bodies can be limited and clinically quite harmless. However, the same cells also occur as part of generalized and much more serious processes such as antigen-antibody reactions (hypersensitivity reaction), of course. Giant cells in such more serious situations are found next to the antigen - or they contain this in their protoplasm. It is very important to separate simple foreign body reaction of the harmless and limited kind from generalized granulomatous inflammation. The localized presence of epithelioid cells and foreign body giant cells by itself is not sufficient to diagnose a systemic granulomatous disease process. Mutton-fat KP's on the posterior corneal surface are a good example of a granulomatous reaction, that is not fully developed due to the lack of vascular supply. 
The number and size of nuclei in a foreign body giant cell are an indication of its digestive activity: the more and the larger the nuclei in relation to the size of the whole cell, the greater the cell's activity. It seems that the presence of giant cells always is an indication of a substance, that needs to be separated from the surrounding tissues and phagocytized. However, this substance does not have to be foreign in the true sense. It can also be tissue substance, that has "degenerated" and, thus, elicits a similar response. The process of phagocytosis can sometimes be recognized histologically by the presence of vacuoles in the protoplasm or a so-called foamy protoplasm of giant cells. Special stains can be used to demonstrate the nature of substances in these vacuoles in some cases. A fat stain, for example, will reveal the lipids in the vacuoles of giant cells in a chalazion, that are the cause of the lid granuloma.

Extremely large foreign body giant cells are frequently found on the surface of intraocular lens implants [4-8]. They are flat and extended on the plastic surface of these implants as well as on the attached haptics. The giant celly typically are part of cellular membranes on these implants and they occur in different shapes and sizes with varying arrangements of their nuclei and in different associations with other cells. They may contain pigment granules and vacuoles of different kinds. It is the purpose of the present paper, to start a cytological description of these giant cells on lens implants in their different developmental stages and appearances.

\section{Cytological Description}

Case 1: The right eye of an 81 year-old female had an intracapsular cataract extraction with placing of an anterior chamber implant of the Choyce type in 1979. This was said to have been very successful for about a year. Then, the patient experienced slow vision loss in the eye. When she was seen again on 12-1-82, a large choroidal tumor was found in the eye. The clinical diagnosis of a malignant choroidal melanoma was made and the eye was enucleated on 1-22-82. Histopathological evaluation revealed a large choroidal melanoma of an epithelioid type without direct extraocular extensions. The tumor had not broken through Bruch's membrane. It involved the choroidal midperiphery on the nasal side and measured $8 \times 6 \times 4 \mathrm{~mm}$. The central retina was in place and it had signs of cystoid macular edema. The vitreous was detached and retracted, but the vitreous face was intact. Iris and ciliary body exhibited some mononuclear infiltration. The iris was distored and scarred peripherally as a result of the anterior chamber lens implant.

Implant cytology studies $[4,7]$, revealed a cellular membrane on the implant. In the region of the supporting feet of the Choyce lens this membrane was composed almost entirely of large foreign body giant cells with groups of small fibroblast-like cells mainly in the interspaces (Fig. 1). In the optical zone the membrane mainly contained fibroblast-like cells with only occasional giant cells. Almost all the giant cells exhibited target-like accumulation of the numerous nuclei in their centers (Figs. 1-3). These centers were in most giant cells involved with a deeply eosinophilic substance, that partly obscured the accumulated nuclei in the $\mathrm{H}$ and E-stained preparations. The cells had large empty-appearing vacuoles in their protoplasm as well as in their nuclear zone (Figs. 2 and 3). The vacuolic change in the center was associated with degeneration of nuclei in some instances (Fig. 3). There also were small vacuoles seen mainly in the protoplasm of some of the very well preserved giant cells (Fig. 2). It was of special interest, to see that the number of the small fibroblast-like cells was increased directly around some of the giant cells and in many areas these had started to extend from the interspaces to cover parts of the giant cells (Figs. 1-3).
Case 2. This 86 year-old female had intracapsular cataract surgery with a Choyce-type implant in her right eye in October 1980. Vision was $20 / 40$ at one time soon after surgery, but glaucoma due to pupillary block developed and an iridectomy was done to relieve this. A central scotoma associated with a swollen optic disk was recognized one year after surgery and optic neuritis was diagnosed by the surgeon. On 12-18-81 I examined the eye and vision was 20/400. Applanation tonometry revealed an intraocular pressure of $7 \mathrm{~mm} \mathrm{Hg}$. Partly pigmented KP's were present on the cornea and the anterior chamber implant was partly luxated with one foot on the ciliary body. Advanced cystoid macular edema explained the central scotoma. The implant was removed on 12-21-81 - 14 months after its original implantation.

Implant cytology revealed a cellular membrane mainly composed of large and very large foreign body giant cells as well as densely arranged groups of small fibroblast-like cells in the interspaces. The giant cells had central nuclei, that were clearly visible in some instances (Fig. 4). In other instances, however, the central nuclei stained poorly or were replaced by accumulations of small vacuoles with distinct limits (Fig. 4). The fibroblast-like cells looked active and were preserved, but they did not extend onto the protoplasm of the giant cells.

Case 3 . This 62 year-old male had extracapsular cataract extraction with placement of a Binkhorst implant on 12-11-79. The operation was a success and the patient is said to have had good vision, until he died on $8-31-81$ - more than one and a half years later. The implant became available for lens cytology study through the Eye Bank program.

The implant was covered by a delicate membrane containing large foreign body giant cells and relatively few fibroblast-like cells of irregular distribution (Fig. 5). The large giant cells were of irregular shape and had distinctly staining nuclei - often arranged in several groups or piles within one cell. Most of these giant cells had extensive pigment granules in some part of their protoplasm, while other parts were clear (Fig. 5). Some of the pigment accumulations were contained in large protoplasmatic vacuoles. All the cells on this lens were arranged in a monolayer - the small cells did not extend onto the clearly defined giant cells.

Case 4. This 86 year-old male with adult onset diabetes had an intracapsular cataract extraction with implantation of a medallion lens in August 1980. There was no vireous loss, but the vitreous face prolapsed into the anterior chamber through the pupil and an unusually large peripheral iridectomy at 12 o'clock made the fixation of the lens by its supporting iris suture difficult. The implant ended up sitting high in the pupil with one supporting loop on the ciliary body. Vision remained poor after surgery due to distinct cystoid macular edema - and was $20 / 60$ at its best about one year after surgery. A membrane exhibiting irregular pigmentation and some distinct and slightly elevated round or oval bumps was seen on the lens by slit lamp. In May 1982 the eye developed rubeosis without glaucoma. It also had a continuous iritis and further vision decrease to counts fingers in 1 foot eccentrically. The implant was removed on 5-17-82.

The round or oval bumps, that had been seen clinically by slit lamp could be histologically identified as large foreign body giant cells in the membrane of the anterior surface of the implant (Fig. 6). These giant cells had poorly defined cell borders and large non-distinct vacuoles as well as some pigment granules in their protoplasm. The cell's numerous basophilic nuclei were accumulated in their centers. These centers also exhibited a very dense eosinophilic stain (Fig. 6). Small fibroblast-like cells not only surrounded these giant cells in a monolayer, but they also extended onto the giant cell protoplasm in a few areas (Fig. 6). This implant also serves well, to show the giant cells on its rod-like haptics (Fig. 7). On these haptics the foreign body giant cells were smaller and again they were part of a thin continuous membrane.

Case 5. An 80 year-old male with severe rheumatoid arthritis had an intracapsular cataract extraction with a Choyce anterior 


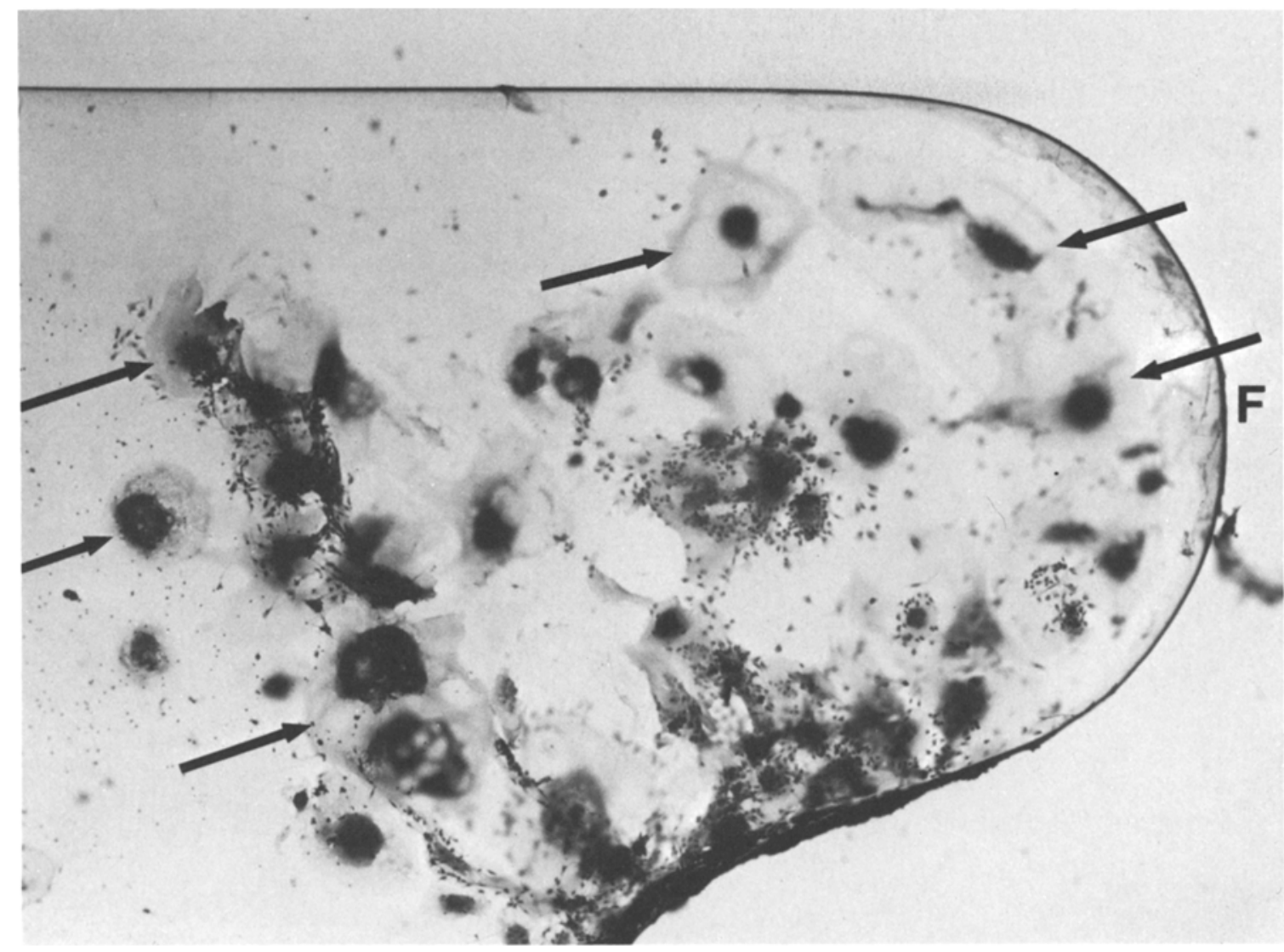

Fig. 1. First case, footplate $(F)$ of Choyce lens implant with numerous large foreign body giant cells (arrows). The giant cells have central accumulations of nuclei and they are not all in focus. Accumulations of small fibroglast-like cells seen around the giant cells and more fibroblast-like cells diffusely distributed in the interspaces. - Implant cytology technique, $\mathrm{H}$ and $\mathrm{E}$ stain, microphotograph $\times 30$

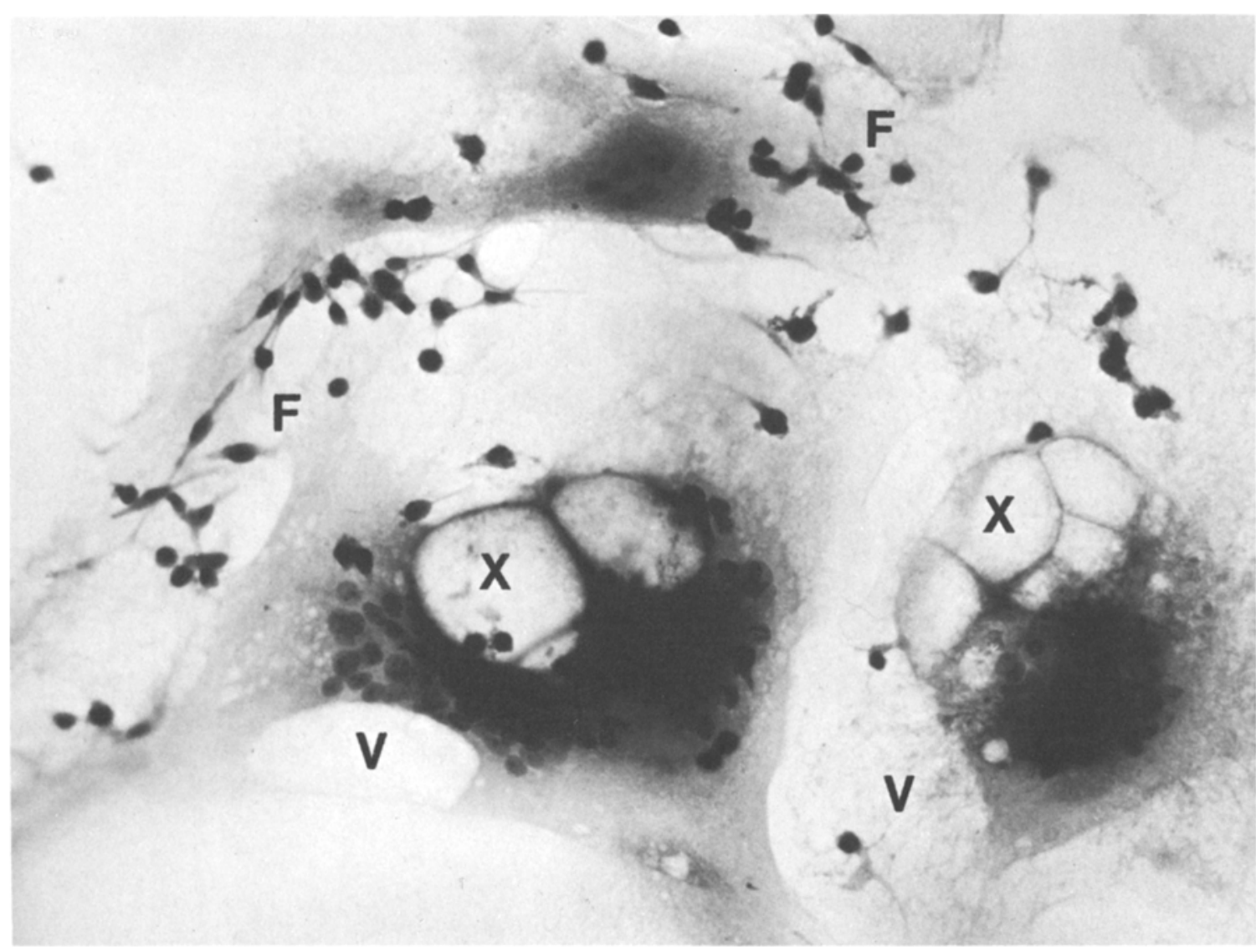

Fig. 2. First case, higher power of foreign body giant cells with central accumulations of nuclei partly obscured by dense eosinophilic stain. Vacuoles are seen in the protoplasm $(V)$ and in the nuclear zone $(X)$. Fibroblast-like cells $(F)$ are accumulated around the giant cells and have grown onto their protoplasm in part. - Implant cytology technique, $\mathrm{H}$ and $\mathrm{E}$ stain, microphotograph $\times 200$ 


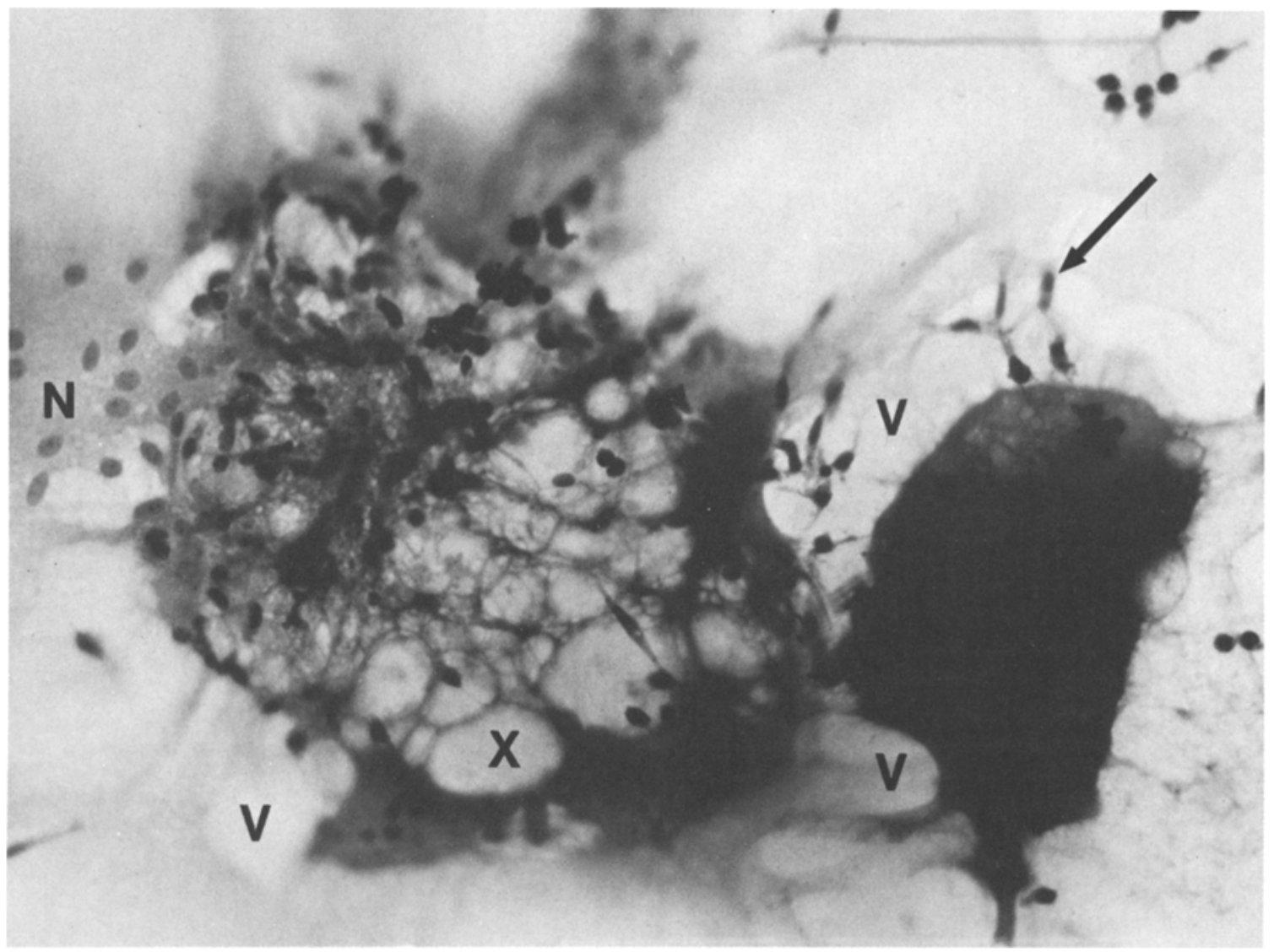

Fig. 3. First case, two large foreign body giant cells. The left one shows vacuoles $(X)$ in the nuclear zone associated with nuclear degeneration. Well preserved nuclei $(N)$ seen to the left. The right giant cell has dense eosinophilic staining of the nuclear zone with small vacuoles. Both cells have protoplasmatic vacuoles $(V)$. Fibroblast-like cells have grown onto the giant cell protoplasm in some areas (arrow). - Implant cytology technique, H and E stain, microphotograph $\times 200$

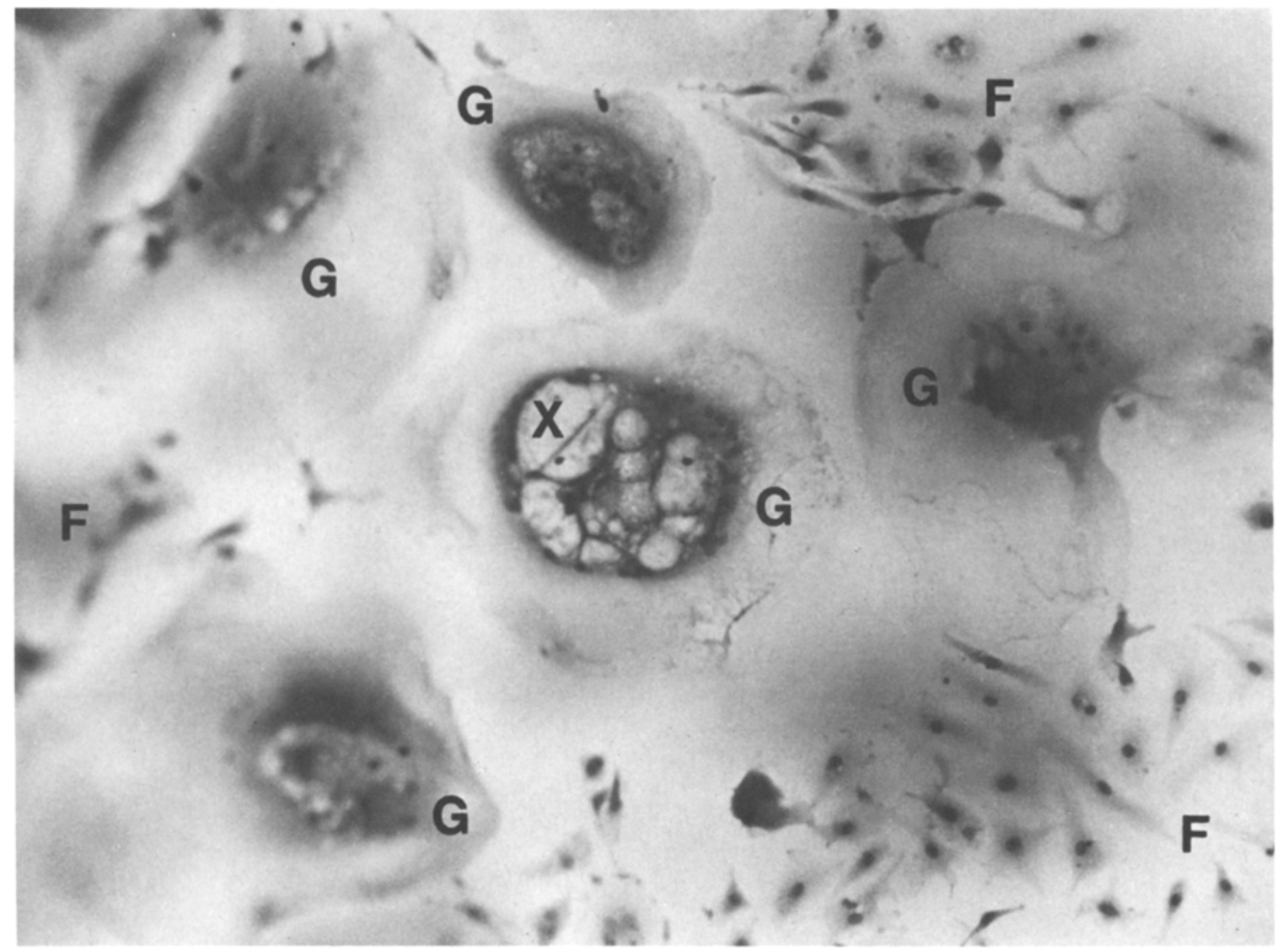

Fig. 4. Second case, densely arranged foreign body giant cells $(G)$ with active fibroblast-like cells $(F)$ in the interspaces. Some of the giant cells have sharply limited vacuoles $(X)$ in their nuclear zone. - Implant cytology technique, $\mathrm{H}$ and $\mathrm{E}$ stain, microphotograph $\times 200$ 


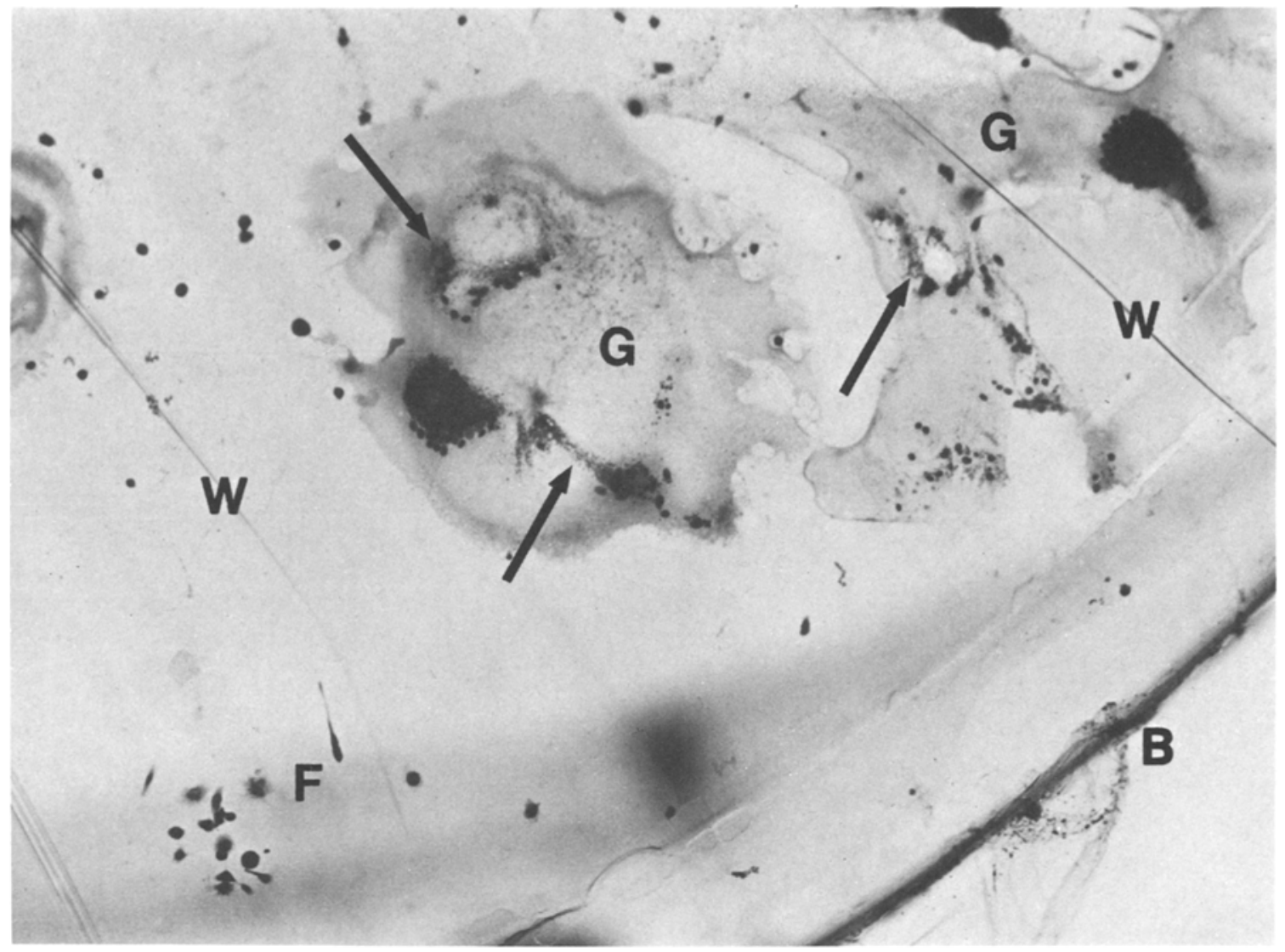

Fig. 5. Third case, large giant cells $(G)$ with pseudopodia-like cell processes. The border $(B)$ of the implant is seen and there are wrinkles $(W)$ in the membrane on the implant. The foreign body giant cells have accumulations of pigment granules in their protoplasm (arrows). Fibroblast-like cells in the interspaces $(F)$ are poorly stained. - Implant cytology technique, $\mathrm{H}$ and $\mathrm{E}$ stain, microphotograph $\times 100$

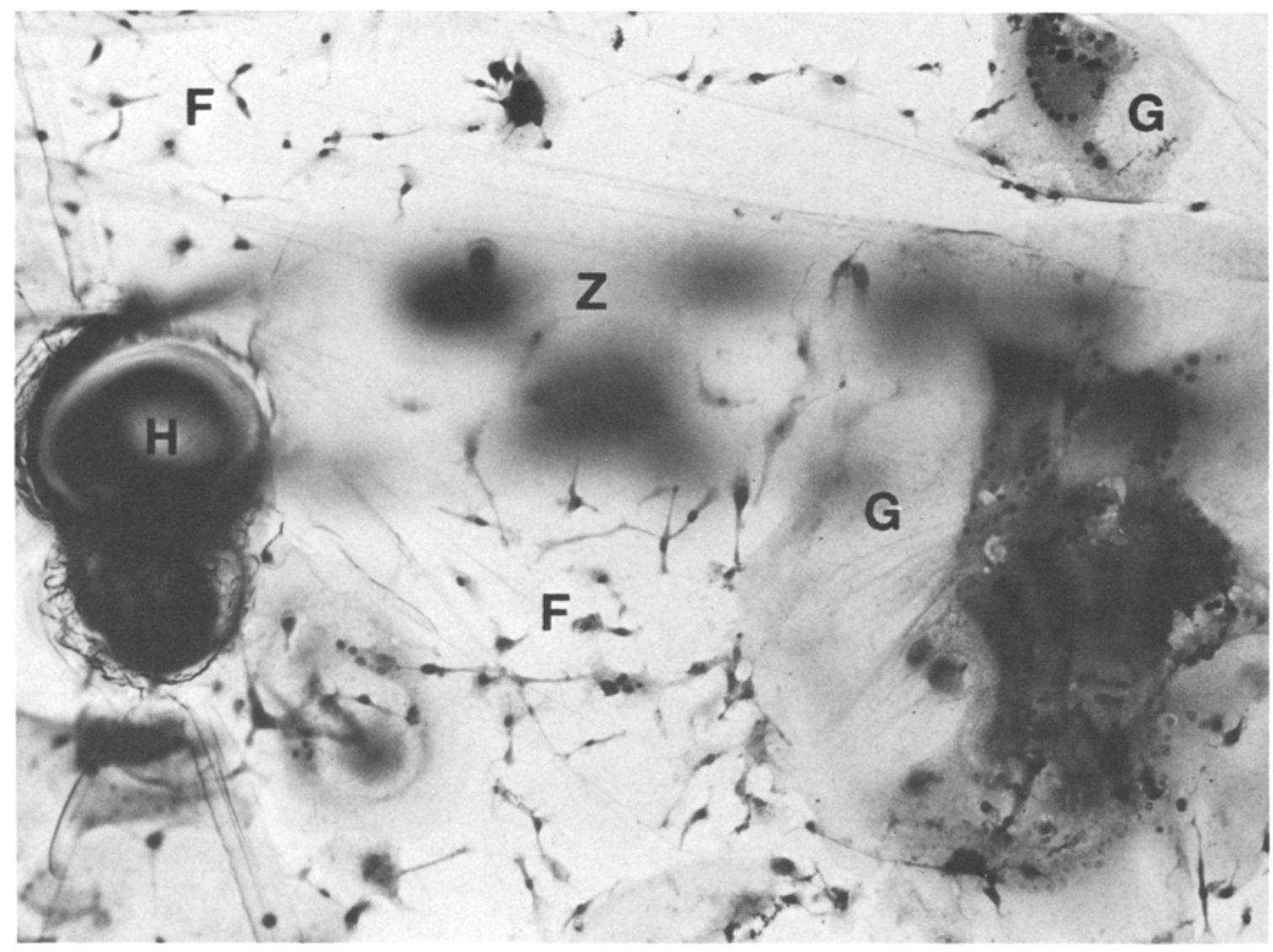

Fig. 6. Fourth case, very large foreign body giant cells $(G)$ next to insertion of haptic $(H)$ in the implant. Giant cells on the other side of the implant $(Z)$ are out of focus. The nuclear zone of the giant cells shows an cosinophilic stain as well as vacuoles. Fibroblast-like cells $(F)$ in the interspaces have started to extend over the giant cells. - Implant cytology technique, $\mathrm{H}$ and $\mathrm{E}$ stain, microphotograph $\times 150$ 


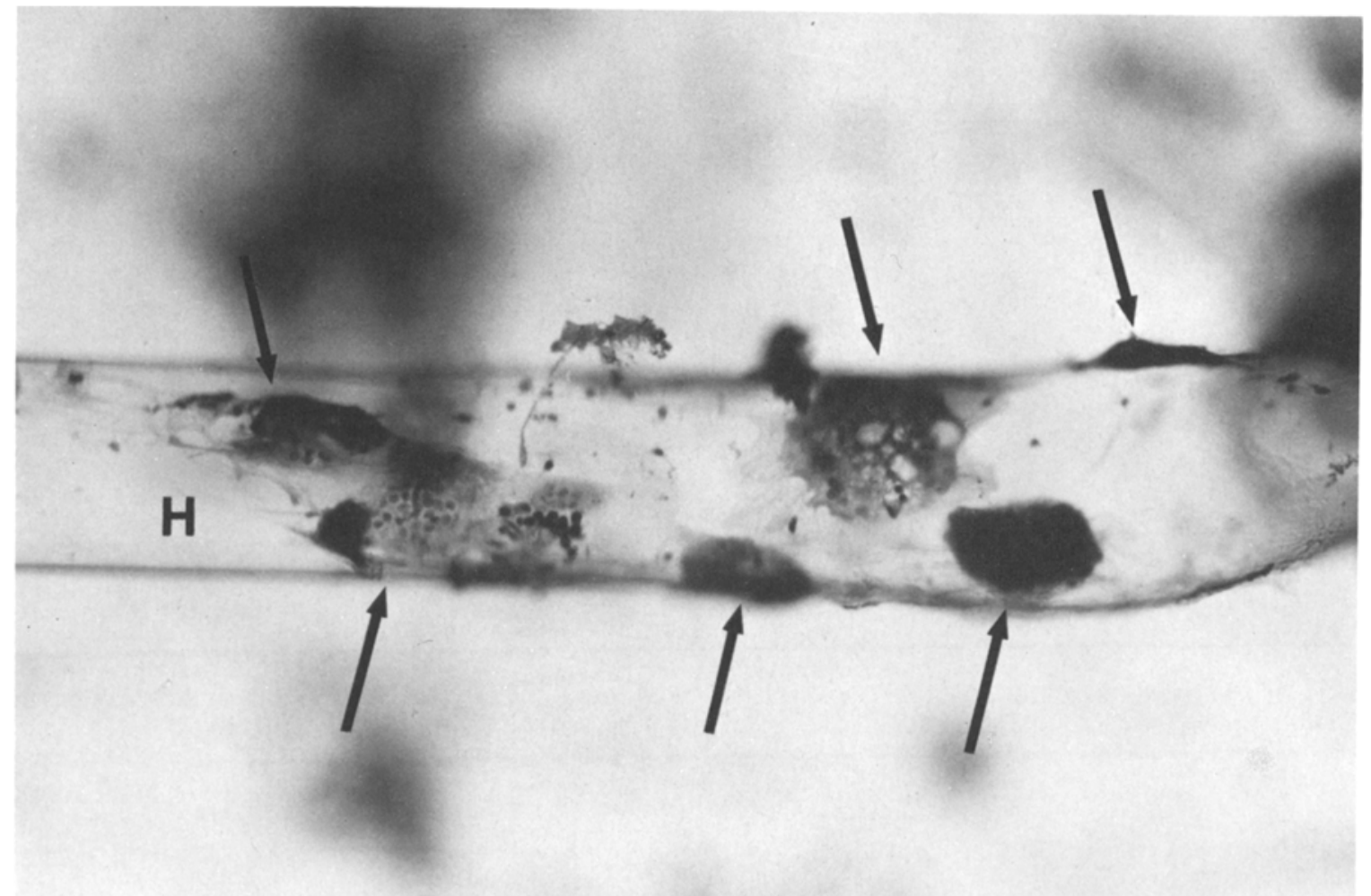

Fig. 7. Fourth case, rod-like haptics with smaller giant cells (arrows). Nuclear zone stains strongly eosinophilic and some of the cells have vacuoles in this zone. Few fibroblast-like cells seen in interspaces. - Implant cytology technique, $\mathrm{H}$ and $\mathrm{E}$ stain, microphotograph $\times 150$

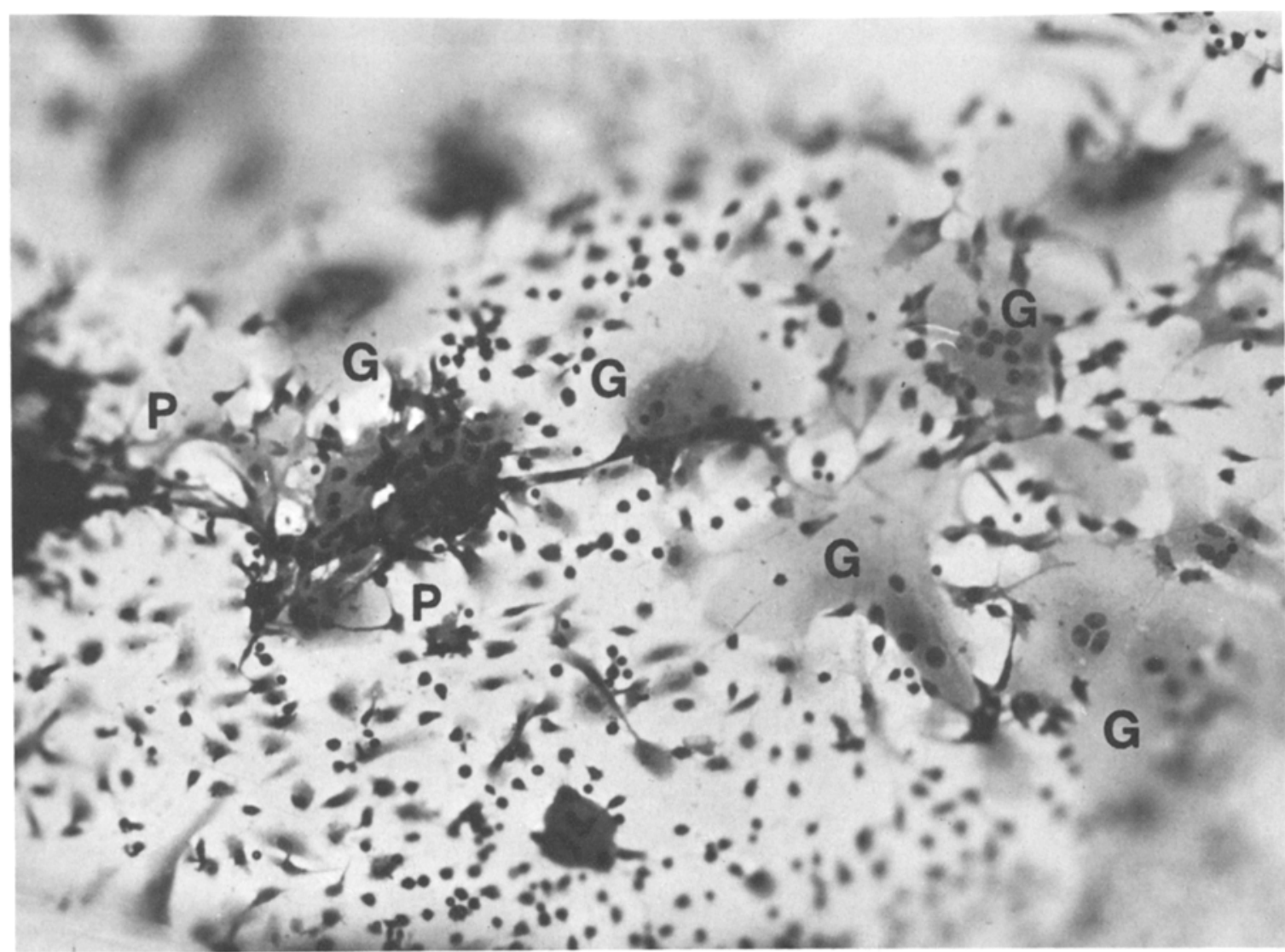

Fig. 8. Fifth case, giant cells $(G)$ of irregular shape with pale nuclei of irregular distribution partly covered by proliferating fibroblast-like cells originating in two growth centers $(P)$. Single fibroblast-like cells and mononuclear inflammatory cells are seen all over the surface of the implant. - Implant cytology technique, $\mathrm{H}$ and $\mathrm{E}$ stain, microphotograph $\times 150$ 


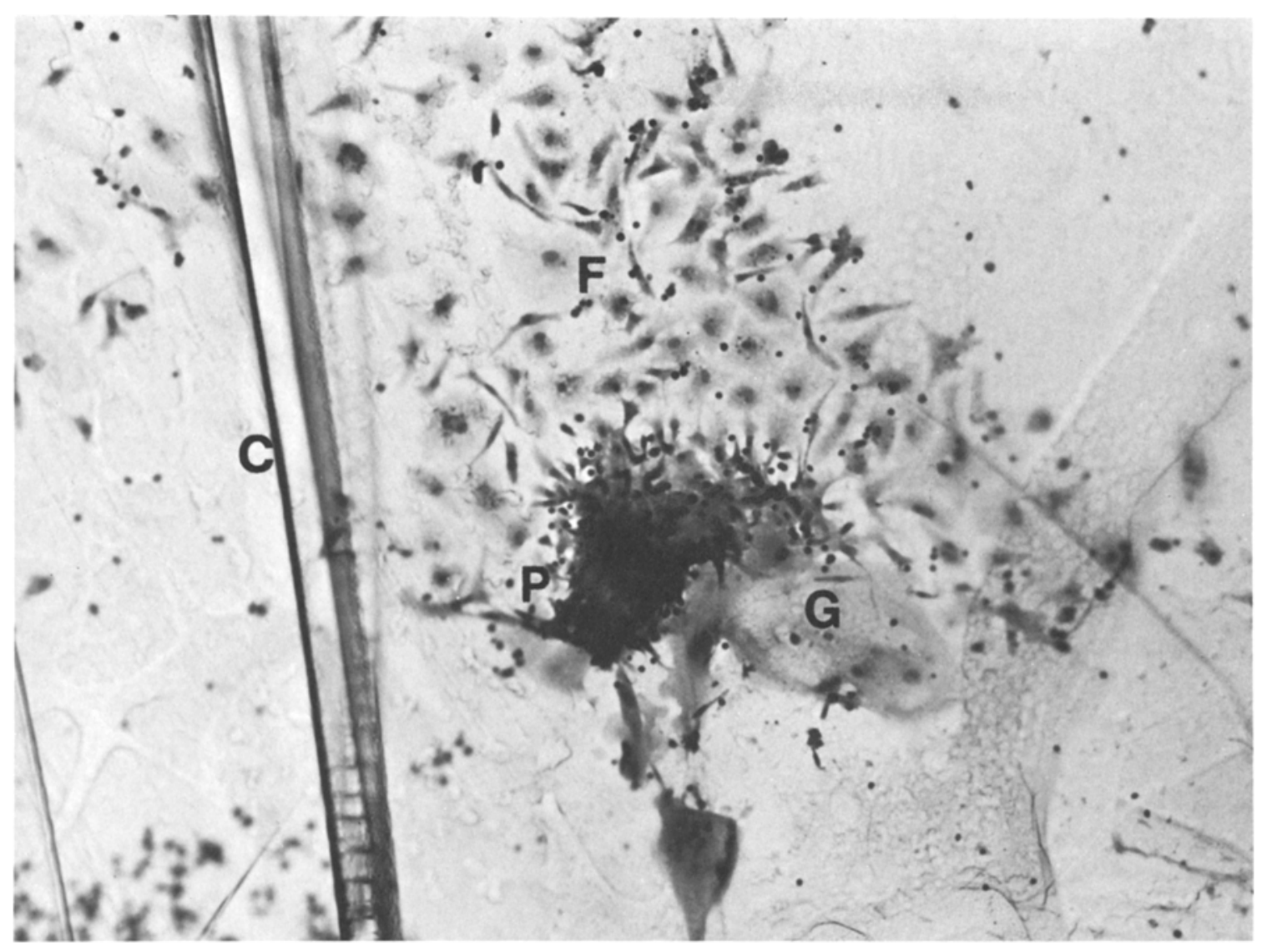

Fig. 9. Fifth case, growth center of proliferating fibroblast-like cells $(P)$ partly covering a degenerating giant cell $(G)$. Active fibroblast-like cells $(F)$ seen to surround the growth center. A crack in the implant $(C)$ is an embedding artifact. - Implant cytology technique, $\mathrm{H}$ and $\mathrm{E}$ stain, microphotograph $\times 150$

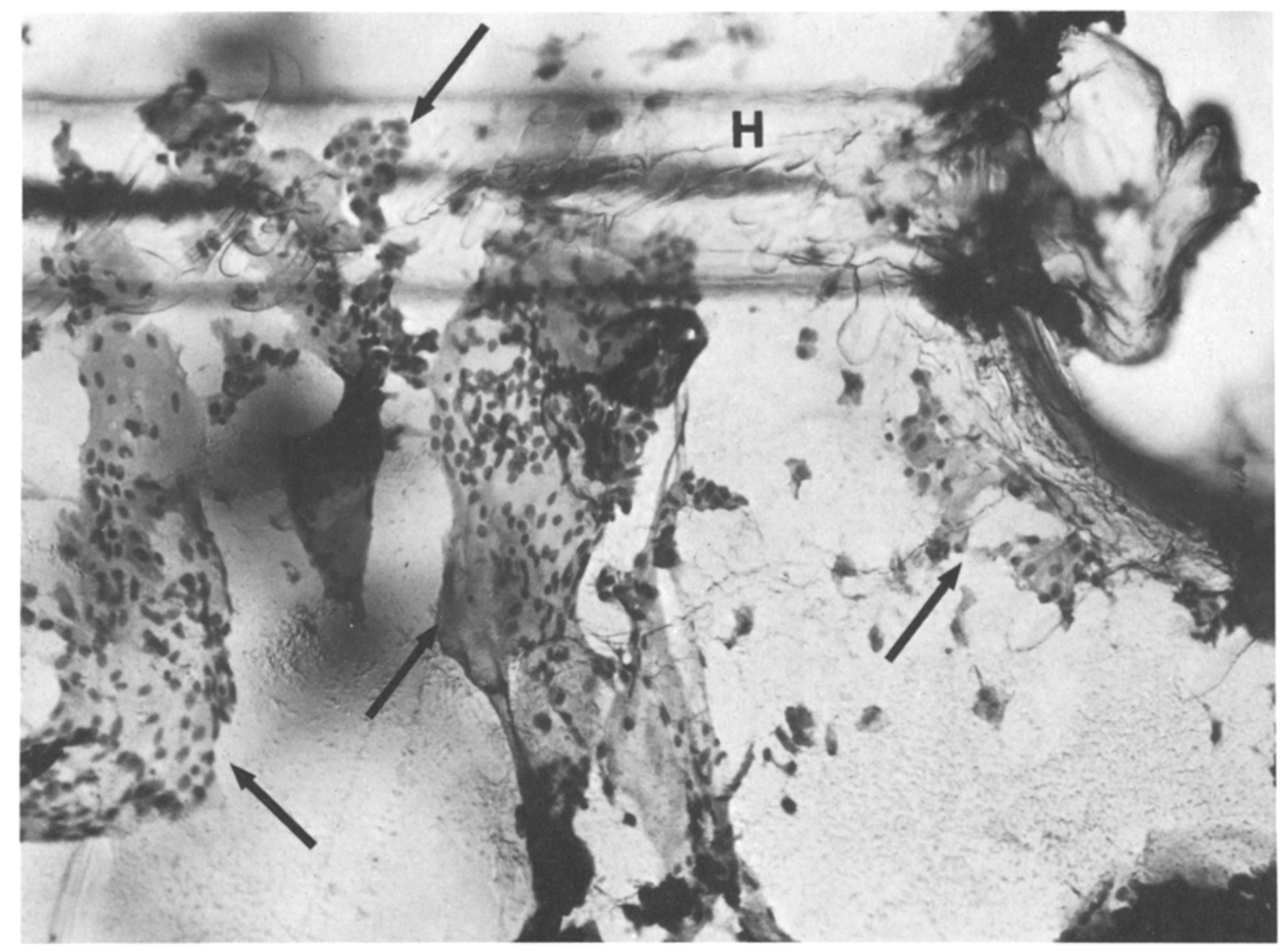

Fig. 10. Sixth case, partly fragmented giant cells (arrows) on the surface of implant with great numbers of nuclei evenly distributed all through their protoplasm. Part of the haptics $(H)$ seen out of focus and a hole in the lens on the upper right. - Implant cytology technique, $\mathrm{H}$ and $\mathrm{E}$ stain, microphotograph $\times 125$ 


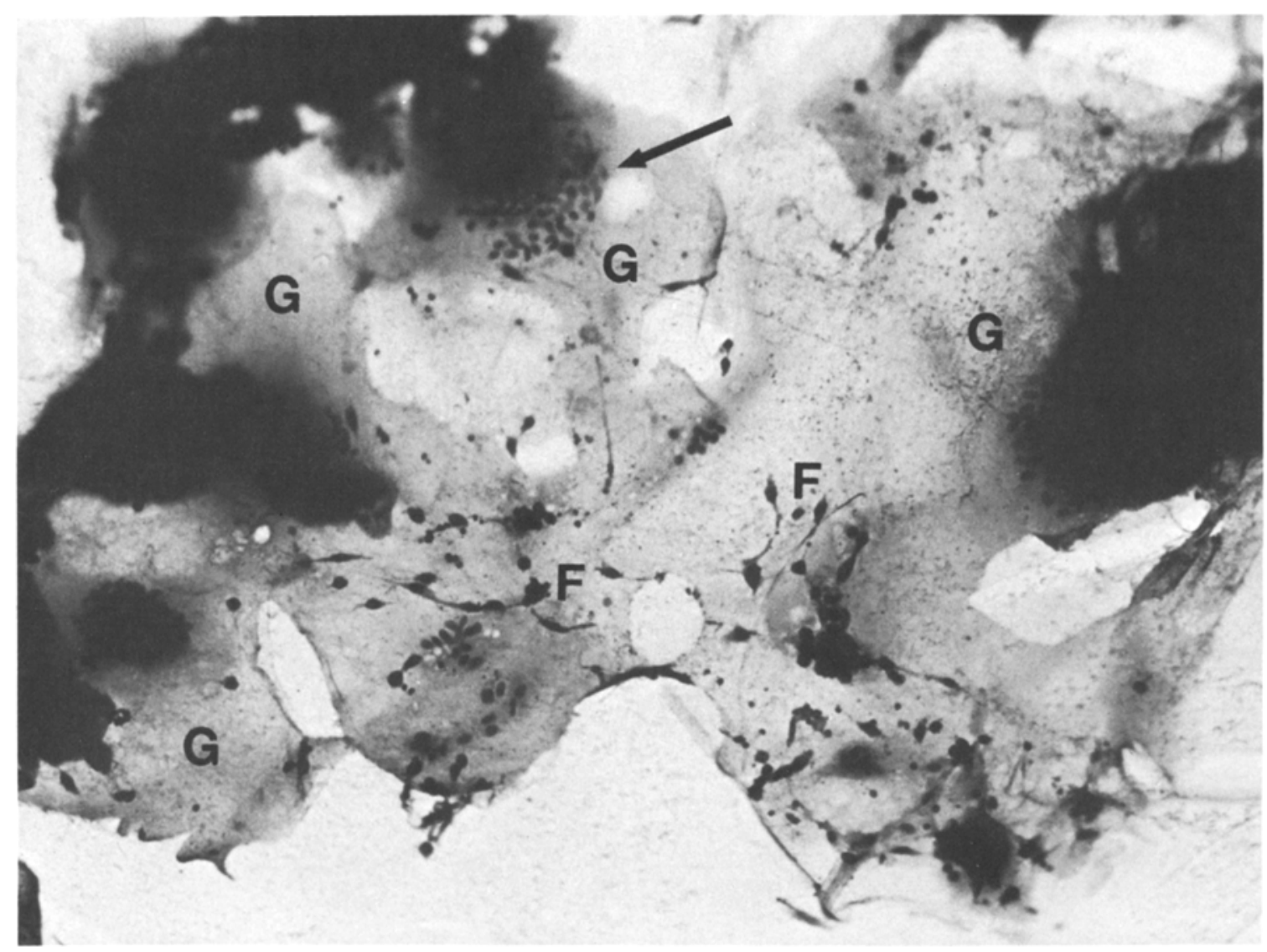

Fig. 11. Sixth case, continuous sheath of large giant cells $(G)$ with dense eosinophilic stain of their nuclear zone. The central nuclei (arrow) well preserved in some of the cells. Fibroblast-like cells $(F)$ have extended onto the outer surface of the giant cell protoplasm. Pigment granules seen diffusely in the giant cell protoplasm. - Implant cytology technique, $\mathrm{H}$ and $\mathrm{E}$ stain, microphotograph $\times 125$

chamber implant in May 1977. Postoperative vision was reported by the patients as good. However, since July 1981 bullous keratopathy gave trouble and on that basis the patient developed a corneal ulcer in March 1982. The eye had to be eviscerated on 3-13-1982.

The implant in this case exhibited a continuous membrane with highly active fibroblast-like cells (Fig. 8). These cells formed growth centers and extended on the surface of an old cellular membrane, that was composed of a monolayer formed by foreign body giant cells and more inactive fibroblast-like cells in a somewhat regular arrangement. Some of the giant cells in the original membrane were active. They had relatively large nuclei of irregular distribution (Fig. 8). Others were clearly degenerating under a cover of layers of proliferating fibroblasts. These giant cells had lost most of their nuclei and had poorly defined borders (Fig. 9). Numerous mononuclear inflammatory cells and some PMN's were also seen on the surface of the monolayer (Fig. 8).

Case 6. This 67 year-old male had an intracapsular cataract extraction with an iris supported implant in 1979. There were difficulties with subluxation of the implant and this had to be surgically repositioned twice. Chronic corneal edema developed and a corneal transplantation was done about one year after the cataract extraction. The graft failed and extensive peripheral anterior synechiae as well as glaucoma developed. A repeat corneal graft with removal of the lens implant was done on 5-17-82. The implant was found encapsulated in dense fibrous tissue, that was loosely connected to the cornea on its anterior aspects. Posterior to the implant this fibrous capsule contained parts of iris, organized vitreous, and peripheral retina. After opening of the fibrous capsule, the implant was not found to be firmly attached and could be removed from it easily.
The observation of a well-defined and continuous cellular membrane covering this implant in addition to the fibrous capsule was a surprise. In some parts extremely large foreign body giant cells exhibited bizarre and irregular shapes. The nuclei in these giant cells were of rather regular size and distribution all through the extensive protoplasm giving the cells a tiger-skin-like histological appearance (Fig. 10). Large giant cells in other areas of the surface of this implant had central piles of nuclei - almost invisible due to accumulation of a dense eosinophilic substance in the nuclear zone (Fig. 11). Small active giant cells and epithelioid cells mixed with fibroblast-like cells were seen in the interspaces (Figs. 10 and 11), but the fibroblast-like cells were not very active or proliferating. However, they extended onto the surface of degenerating giant cells in some areas (Fig. 11).

\section{Discussion}

It is not unusual for foreign body giant cells on intraocular lens implants to grow to a diameter of about $0.5 \mathrm{~mm}[5$, 7]. Thus, they are easily visible by slit lamp and resemble distinct and slightly prominent round or oval spots with or without pigmentation. They are spread out on the clear substance of the implants and can be studied in detail by the lens implant cytology technique $[4,7]$. Features, that are microscopically visible with the use of this simple technique and that can be recorded photographically, are their number, location on the implant, size, shape, nature of cell borders, number as well as arrangement of nuclei, condition as well as staining properties of protoplasm, protoplasmatic inclusions, and relations to other cells on the implant. 
The cells lining the normal lens do not have direct blood supply, but they obtain their nutrition from the fluids of the inner eye. In a similar way, cells on lens implants live like cells in tissue culture and depend on the aqueous humor for their nutrition. The principle, that one cell growing on top of another can take away the food supply of the deeper cell, is essential for an understanding of the growth conditions on implants. It is also important to recognize, that the fluids in the quiet conditions of a normal eye contain less protein than those of an irritated eye. Iridocyclitis and hypotony, for example, go along with leakage of proteinaceous substances - and, thus, improve conditions for growth of cells on lens implants. Both, atropine and steroids, for another example, are effective against vascular leakage and, thus, cut down on the conditions for growth of these cells. Study of the cell life on implants soon reveals evidence of the fight for life among different cell types, that is typical for the life in all its primitive forms [9]. Stages of great activity are seen in cells on implants under different conditions. Some conditions obviously favor the growth of histiocyte-related cells - including foreign body giant cells - on lens implants. These cells appear first on newly placed implants and with time the fibroblast-like cells tend to take over [5]. It seems, that the histiocyte-related cells disappear, when the eye becomes adjusted to the implant and stable conditions with a firm proteinaceous membrane are achieved. The fibroblast-like cells in a very orderly distribution permanently populate the membranes on lens implants, but the formation of such permanent membranes takes years of clinically perfect healing and acceptance of the implant [5].

Foreign body giant cells in membranes on lens implants may occur in a continuous sheet of large cells or they may be isolated occurrences. It is common, to see all stages of their development from single sessile histiocytes over epithelioid cells and small giant cells to the very large and flat cells. In general, giant cells are most common on lens implants studied within the first two years after implantation. Giant cells often cover only one part of an implant - and may be absent on others. Border areas and corners next to holes or insertions of haptics are common locations for single remaining giant cells in stable membranes, that are otherwise dominated by fibroblast-like cells. Giant cells are also common on haptics and supporting sutures - and they seem to stay on these more delicate structures longer than on the flat surfaces of the main body of the implants.

The size of the foreign body giant cells on lens implants is extraordinary. Their shape is mostly round or oval, but bizarre forms with long and irregular pseudopodia are seen in active membranes. Under relatively inactive conditions the borders of giant cells are well defined. Under active conditions the borders can be invisible after staining with $\mathrm{H}$ and $\mathrm{E}$.

I have counted up to about 100 nuclei in the protoplasm of one large giant cell in an active membrane on a lens implant. In active stages these nuclei can be rather evenly distributed all through the protoplasm of these cells giving them a tiger skin-like histological appearance. Most commonly the nuclei are accumulated in one region - usually target-like in the center of their protoplasm. Inactive membranes often exhibit in the nuclear zone a deeply eosinophilic stain, that is histologically more or less obscuring. The nuclear zone may also contain numerous small and sharply limited vacuoles. The presence of these vacuoles usually is associated with degeneration of nuclei. The nuclei are also sometimes seen to simply have faded, when massive fibroblastic overgrowth has covered a giant cell and probably taken away its nutrition.

The protoplasm of giant cells commonly exhibits vacuoles similar to the vacuoles seen in cells of this kind in histological sections. Those vacuoles are usually believed to be associated with phagocytic activity. The vacuoles of the giant cells on lens implants either appear empty or they concontain pigment granules. Diffuse pigmentation may be seen all through the protoplasm [6]. Most of the protoplasm of the otherwise healthy-looking giant cells on lens implants appears rather empty and clear. Eosinophilic stain of the protoplasm in the nuclear zone is commonly associated with loss of nuclei and other signs of degeneration. Degenerating giant cells overgrown by fibroblast-like cells, for example, have a denser and diffusely more eosinophilic protoplasm as compared to active and stable giant cells. It is important to emphasize, that reasonably successful implants have monolayers of cells on their surface - and these are spread out in a very flat arrangement. Growth of cells on implants in more than one layer appears to be an indication of trouble. However, survival of typical cellular membranes on implants have been observed in situations, where a fibrous capsule had totally ensheathed the implant and all the cells on it [9].

Giant cells are the most juicy and most active cell element in cellular membranes on lens implants. With all their many nuclei they are suspected to have a high metabolism. It must be difficult for these cells to compete with the very frugal fibroblast-like cells. When we consider, furthermore, the common presence of mild iridocyclitis with its typical ups and downs and the additional influences of changes in eye pressure as well as the variations in vascular leakage due to application of steroid eye drops, we can easily imagine the problems in the daily life of a giant cell. It should be the clinicians aim, to cut down on the possibility of the opportunistic growth of these giant cells. Good indications, minimal surgical trauma, the most inert plastic material, clean technique, and the best possible control of postoperative iridoclitis and hypotony are all believed to contribute to this goal.

\section{References}

1. Wolter JR (1960) The macrophages of the human vitreous body. Amer J Ophth 49:99-107

2. Wolter JR (1982) Leaky cystoid macular edema attracting vitreous macrophages. Ophthalmic Surg 13:568-571

3. Fitzpatrick TB, Eisen AZ, Wolff K, Freedberg IM, Austen KF (1979) Dermatology in General Medicine. McGraw-Hill, New York, p 1004

4. Wolter JR (1982) Lens implant cytology. Ophthalmic Surg (in print)

5. Wolter JR (1982) Cell life on the surface of lens implants. von Graefes Arch Ophth 218:244-249

6. Wolter JR (1982) Pigment in cellular membranes on intraocular lens implants. Ophthalmic Surg (in print)

7. Wolter JR (1982) A technique for staining cellular membranes on intraocular lens implants. Trans Amer Ophth Soc, in print

6. Kincaid MC, Green WR, Iliff WJ (1982) Granulomatous reaction to Choyce style intraocular lens. Ophthalmic Surg 13:292-299

9. Wolter JR, Felt DP (1982) Fibroblastic activity on failing intraocular lenses. Ophthalmic Surg (in print)

Received June 23, 1982 